\title{
¿Una pintura más? La unicidad en la Virgen de Guadalupe de Ayapango
}

\author{
STRPC, ENCRYM-INAH
}

a imagen de la Virgen de Guadalupe, considerada como milagrosa y de origen sobrenatural a partir de mediados del siglo XVII, fue ganando adeptos hasta que la devoción por la Guadalupana se convirtió en uno de los cultos más importantes del virreinato. Esta fe en aumento se reflejó en su juramento como patrona de la Nueva España por el cabildo de la ciudad de México, en 1746; en su confirmación pontificia y oficio propio, el 12 de diciembre de 1754, y en las magnas celebraciones que le siguieron tanto en la capital como en las provincias de la Nueva España, entre 1756 y 1757 (Cuadriello et al. 2004).

La vasta cantidad de pinturas y esculturas novohispanas — de los siglos XVII, XVIII- y del siglo XIX que representan a la Virgen de Guadalupe, de diversas calidades, dimensiones y temáticas, dan cuenta de la gran devoción ligada a su culto. Esta profusión tiene dos caras: por un lado, la multiplicación de copias del ayate original sirvió para difundir la devoción incluso en términos de "propaganda" y, por el otro, la enorme aceptación de la imagen generó una gran demanda de reproducciones visuales entre distintos estratos de la población.

Con base en estas circunstancias, no es de extrañar que en los últimos 20 años de trabajo del Seminario-Taller de Restauracion de Pintura de Caballete (STRPC) de la ENCRYM-INAH se haya restaurado anualmente al menos una pintura con la imagen guadalupana. Una de las más relevantes es la que se intervino en el año 2009, proveniente del templo de Santiago Apóstol en Ayapango, municipio del estado de México, ubicado a las faldas del volcán Iztaccíhuatl (Figura 1). ¿Qué vale la pena destacar de una pintura más con esta particu-
lar advocación mariana?

Como todo proceso de restauración, el trabajo del STRPC inició con el establecimiento de los límites de la intervención a partir del principio del respeto al bien cultural, para lo cual fue imprescindible reconocer y definir los valores de la obra antes siquiera de suponer qué tratamientos aplicar. Con esta postura, propia del seminario-taller, se busca preservar aquellos significados adscritos al bien y rescatar los que se hallen atenuados por el deterioro presente, para lograr que ese objeto perviva con su unicidad.

FIGURA 1. Rostro de la Virgen de Guadalupe de Ayapango, Estado de México. (Fotografía Daniel Sánchez, 2012; cortesía: STRPC, ENCRyM-INAH). 
FIGURA 2. Aproximación al diseño de

una mariposa de la guirnalda que rodea a la Virgen (Fotografía Daniel Sánchez,

2012; cortesía: STRPC, ENCRyM-INAH).
Ahora bien, en el ámbito específico de la conservación de pintura de caballete, el significado de la noción de unicidad establece dos vertientes: la primera, que deriva del principio generalmente aceptado por la teoría clásica de la restauración, señala que cada objeto cultural debe reconocerse como único e irrepetible; mientras que la segunda acepción, que se desarrolla desde la perspectiva de la imagen, admite una amplia gama de posibilidades, que implican la relación del original con la producción de copias o series de imágenes derivadas de ella (Brandi 1963; Panofsky 1991; Benjamin 1989).

Pareciera difícil plantear la unicidad de las pinturas con la advocación de la Virgen de Guadalupe, ya que la mayoría de ellas respetan el modelo original lo más exactamente posible. Esto se debe a que desde el Virreinato se consideró a la Guadalupana del Tepeyac como una imagen acheropoiética; es decir, de origen sobrenatural, no creada por manos humanas. Modificar una efigie creada milagrosamente hubiera significado sustraer parte de su aura de objeto sagrado, en teoría no debían admitirse variables que entorpecieran su semejanza con la original. El cumplimiento del canon religioso significaba, por tanto, que, al copiar una vera efigie, los artífices debían evitar la novedad (Pereda 2007).

Los pintores novohispanos señalaron las dificultades que imponía el propio carácter milagroso de la Guadalupana, ya que creían que éste les impedía reproducirla correctamente; no fue sino hasta que el reconocido pintor Juan Correa (ca. 1635/1646-1716) sacó una calca del ayate original — con los contornos de la figura y sus rayos - cuando los artistas cercanos a él pudieron lograr imágenes "exactas" (Cabrera 1756). Sin embargo, diversos motivos ocasionaron que ciertas obras guadalupanas presentaran algunas modificaciones respecto de su referente original, sobre todo en razón del desconocimiento del ayate "verdadero" o de sus calcas, de la necesidad de variar el tamaño, de la búsqueda por narrar el milagro, más que por presentar a la Virgen tal y como se había aparecido, o bien de los recursos técnico-pictóricos del autor.

La Virgen de Guadalupe de Ayapango sobresale entre sus análogas debido a que su autor no sólo conoció la imagen original, lo cual es evidente, y probablemente tuvo acceso a la calca de Correa, sino también a que poseía una enorme capacidad artística: su obra, por tanto, no fue la de un mero copista. Como valores particulares de esta pintura destacan, en primer término, la composición

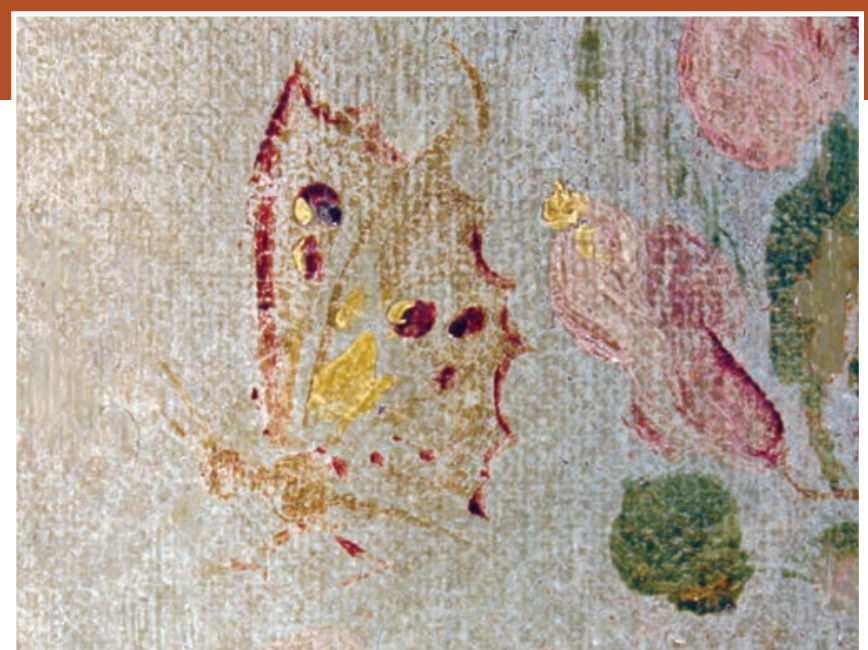

compleja, que incluye: una delicada guirnalda con flores, aves e insectos que enmarcan a la hermosa Guadalupana (Figura 2) y, en cada esquina, escenas inspiradas en los grabados de Matías de Arteaga y Alfaro — publicados en la edición de 1685 del texto Felicidad de México (Becerra Tanco 1685 [1745])—, que narran sus apariciones. Pese a que en estos elementos se observan trazos más sencillos y menos detallados que en los de la Virgen, el conjunto visual, con las flores y recuadros, es arrebatador.

En segundo término, desde el punto de vista artístico, es admirable tanto el manejo de la proporción como la volumetría en la imagen, lo que denota el conocimiento de un artista calificado. Y, en tercer lugar, debe tomarse en cuenta el preciosista y peculiar trabajo de los paños de la Virgen, el manto de color azul verdoso con estrellas doradas y la túnica en tono rosa con elementos fitomorfos: presentan detalles en dorado para dar la apariencia de un textil adamascado, a la usanza de un patrón de entramado tipo sarga. Desde el punto de vista histórico, vale la pena mencionar que, al cotejar varias obras de caballete, se pudo reconocer que el recurso pictórico para representar texturas textiles fue empleado en algunas indumentarias arzobispales de retratos del siglo XVIII (Figura 3).

Adicionalmente, el creador de la obra que nos atañe superó la idea de la copia exacta, al dotarla, mediante el manejo del dorado en la túnica, de una mayor suntuosidad, indudablemente en busca de resaltar aún más el carácter sacro de la imagen. Aunque esta riqueza visual puede equipararse con la de una obra que se encuentra en las bodegas del Museo de la Basílica de Guadalupe, ${ }^{1}$

1 Aunque los alumnos de la ENCRyM-INAH vieron esta obra en el primer semestre de 2004, durante una visita al Museo de la Basílica, desafortu- 


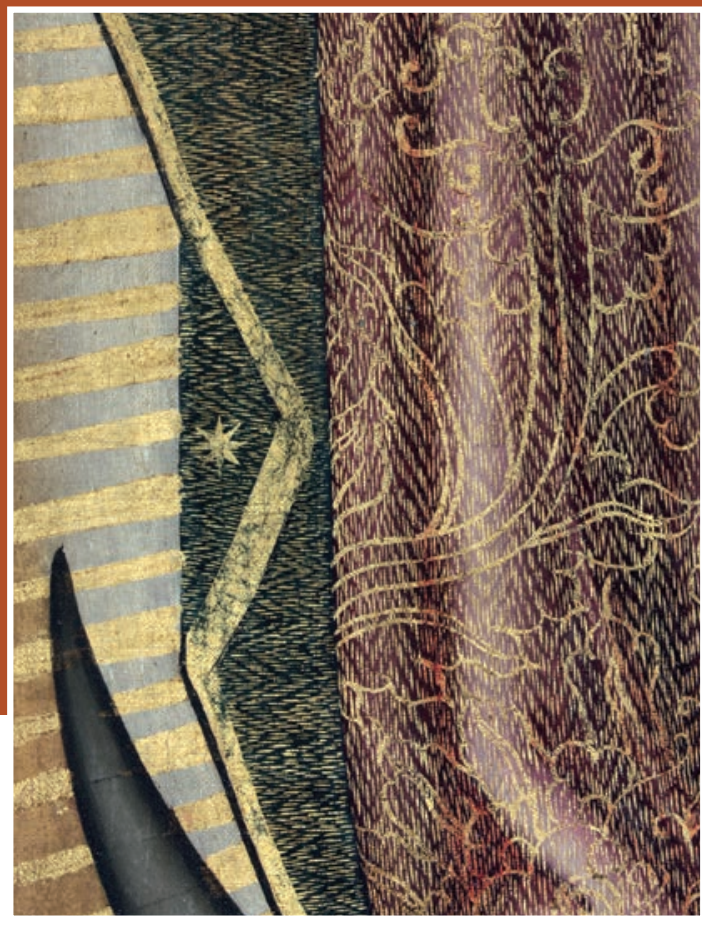

de autor desconocido (quizá el mismo), el lienzo de Ayapango es un ejemplo destacado por su gran belleza y su compleja composición.

La oportunidad de intervenir un objeto tan especial como la Virgen de Ayapango, el cual desde su misma época debió haberse considerado excepcional debido a sus características plásticas inusuales, obligó a los restauradores docentes y alumnos del STRPC a realizar una profunda reflexión acerca de las posturas y los criterios que habrían de sopesarse durante su tratamiento.

Un primer aspecto importante de considerar fue que a su llegada a la ENCRYM-INAH la obra presentaba una problemática de conservación grave, tanto en el aspecto material como en relación con su imagen (Figura 4), por lo que su unicidad estaba comprometida. El mayor deterioro provenía del soporte, que presentaba pudrición, faltantes, roturas y deformaciones severas (Figura 5), lo que ocasionó que los estratos pictóricos sufrieran falta de adherencia respecto del textil, e incluso la formación de cazoletas, ${ }^{2}$ responsables de la destrucción de parte de las escenas de las apariciones.

Además, su barniz se encontraba envejecido, amariIlento y heterogéneo debido a la aplicación con brocha de una resina natural para dar brillo y saturación a los

nadamente no se pudo hacer registro fotográfico de ella, no se conocen datos específicos sobre su procedencia, autor y época de elaboración, ni se sabe de publicación alguna en la que se haya sido mencionada. Sin embargo, consideramos relevante que exista otra imagen similar a la de Ayapango en cuanto al trabajo de los paños.

${ }^{2}$ Escama inestable de forma convexa, generada a partir de la contracción de los estratos pictóricos durante la evaporación de agua y el encogimiento del soporte, tras haber sufrido una humectación directa.
FIGURA 3. Detalle de trabajo adamascado en el textil del manto y la túnica (Fotografía Daniel Sánchez, 2012; cortesía: STRPC, ENCRYM-INAH).

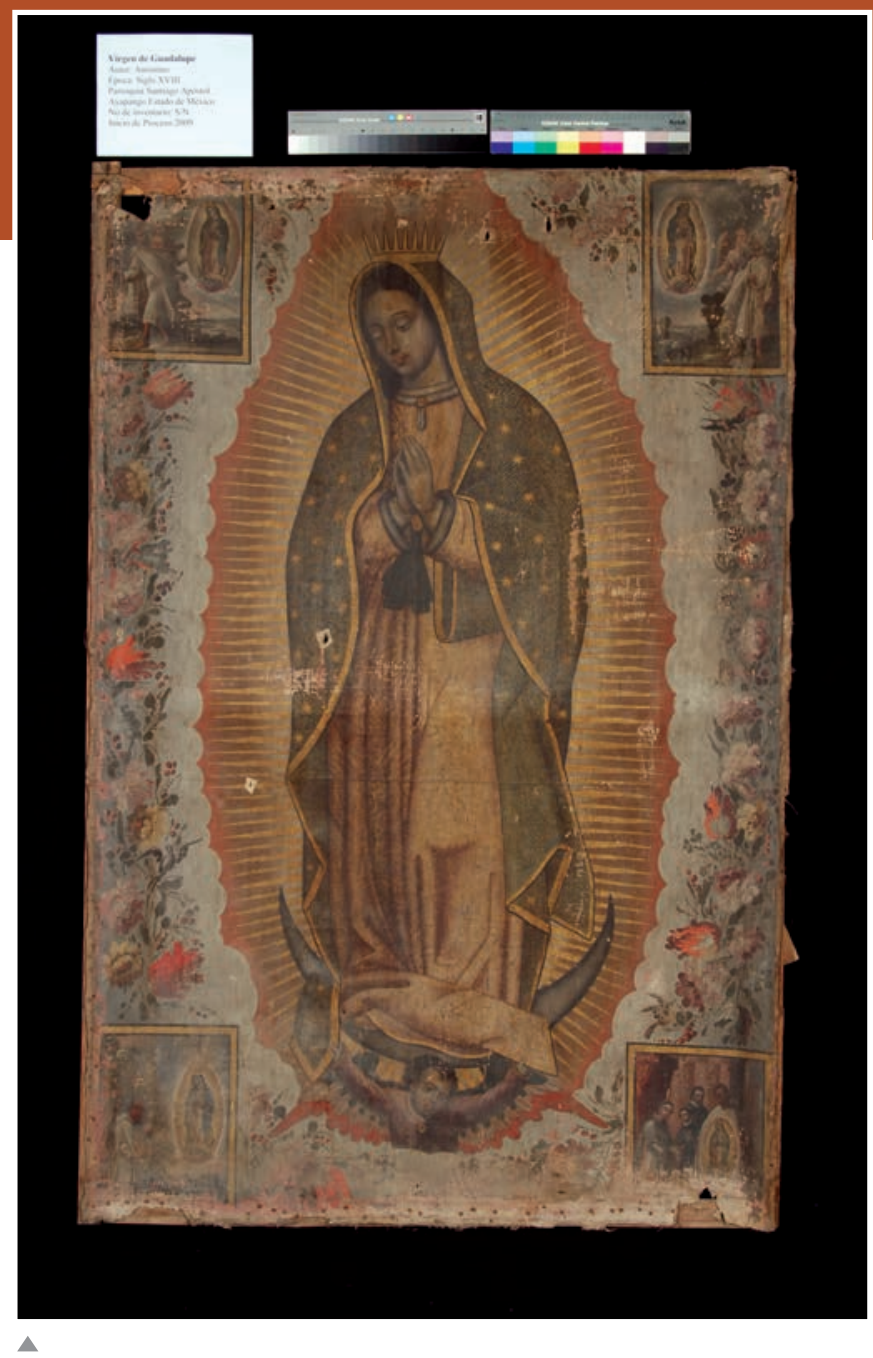

FIGURA 4. Anverso de la Virgen de Guadalupe de Ayapango antes de su restauración (Fotografía Daniel Sánchez, 2012; cortesía: STRPC, ENCRyM-INAH). 

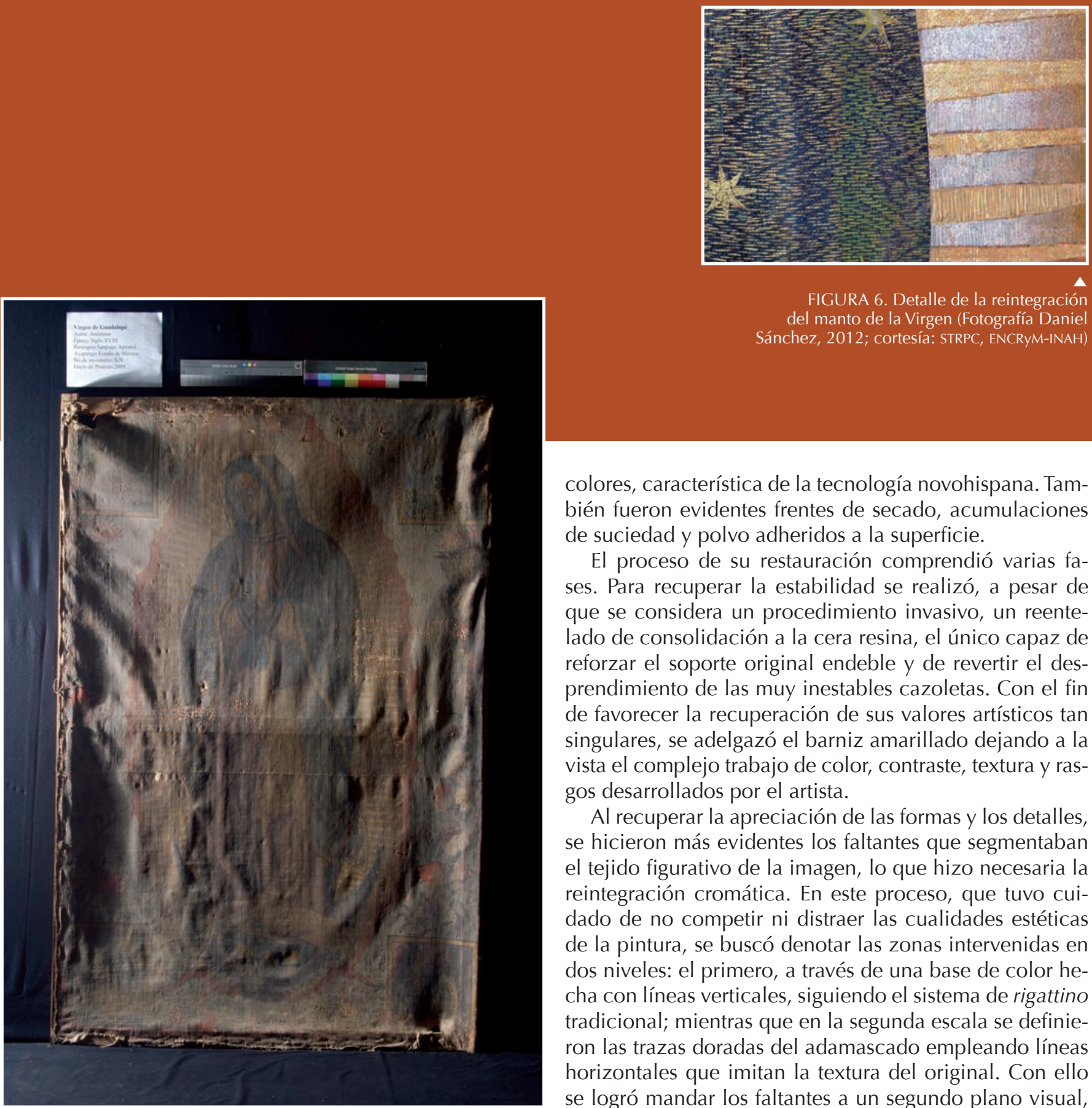

FIGURA 6. Detalle de la reintegración del manto de la Virgen (Fotografía Daniel Sánchez, 2012; cortesía: STRPC, ENCRYM-INAH)

colores, característica de la tecnología novohispana. También fueron evidentes frentes de secado, acumulaciones de suciedad y polvo adheridos a la superficie.

El proceso de su restauración comprendió varias fases. Para recuperar la estabilidad se realizó, a pesar de que se considera un procedimiento invasivo, un reentelado de consolidación a la cera resina, el único capaz de reforzar el soporte original endeble y de revertir el desprendimiento de las muy inestables cazoletas. Con el fin de favorecer la recuperación de sus valores artísticos tan singulares, se adelgazó el barniz amarillado dejando a la vista el complejo trabajo de color, contraste, textura y rasgos desarrollados por el artista.

Al recuperar la apreciación de las formas y los detalles, se hicieron más evidentes los faltantes que segmentaban el tejido figurativo de la imagen, lo que hizo necesaria la reintegración cromática. En este proceso, que tuvo cuidado de no competir ni distraer las cualidades estéticas de la pintura, se buscó denotar las zonas intervenidas en dos niveles: el primero, a través de una base de color hecha con líneas verticales, siguiendo el sistema de rigattino tradicional; mientras que en la segunda escala se definieron las trazas doradas del adamascado empleando líneas horizontales que imitan la textura del original. Con ello se logró mandar los faltantes a un segundo plano visual, $A$

FIGURA 5. Toma fotográfica de la obra con luz rasante, antes de su restauración (Fotografía Daniel Sánchez, 2012; cortesía: STRPC, ENCRYM-INAH). manteniendo congruencia con el tratamiento decorativo de los mantos, de manera que el espectador aprecie las características particulares de los paños de la Guadalupana (Figura 6).

Es nuestra convicción que la intervención realizada en esta obra particular implicó una reflexión acerca de la postura brandiana sobre la denotación de la reintegración respecto al original (Brandi 1963), cuya finalidad fue adecuar este proceso a las necesidades dictadas por la propia obra. Así, de manera análoga al tratamiento de una pintura con un porcentaje alto de abrasión —cuando el rigattino debe simular la vibración del tono de la base de preparación—, en la reintegración de la Virgen 
de Ayapango hubo que superponer líneas verticales y horizontales para rescatar los particulares valores artísticos que determinan su unicidad.

Hoy en día, la Guadalupana de Ayapango continúa dentro de las instalaciones del STRPC, ENCRYM-INAH, debido al meticuloso trabajo de reintegración que implica (Figura 7) y a que aún no se ha determinado a qué nivel de reconstrucción se llevarán las escenas inferiores, intervención que también buscará ser lo más respetuosa de la unicidad de una obra excepcional dentro del corpus histórico, sacro y artístico de nuestro país.

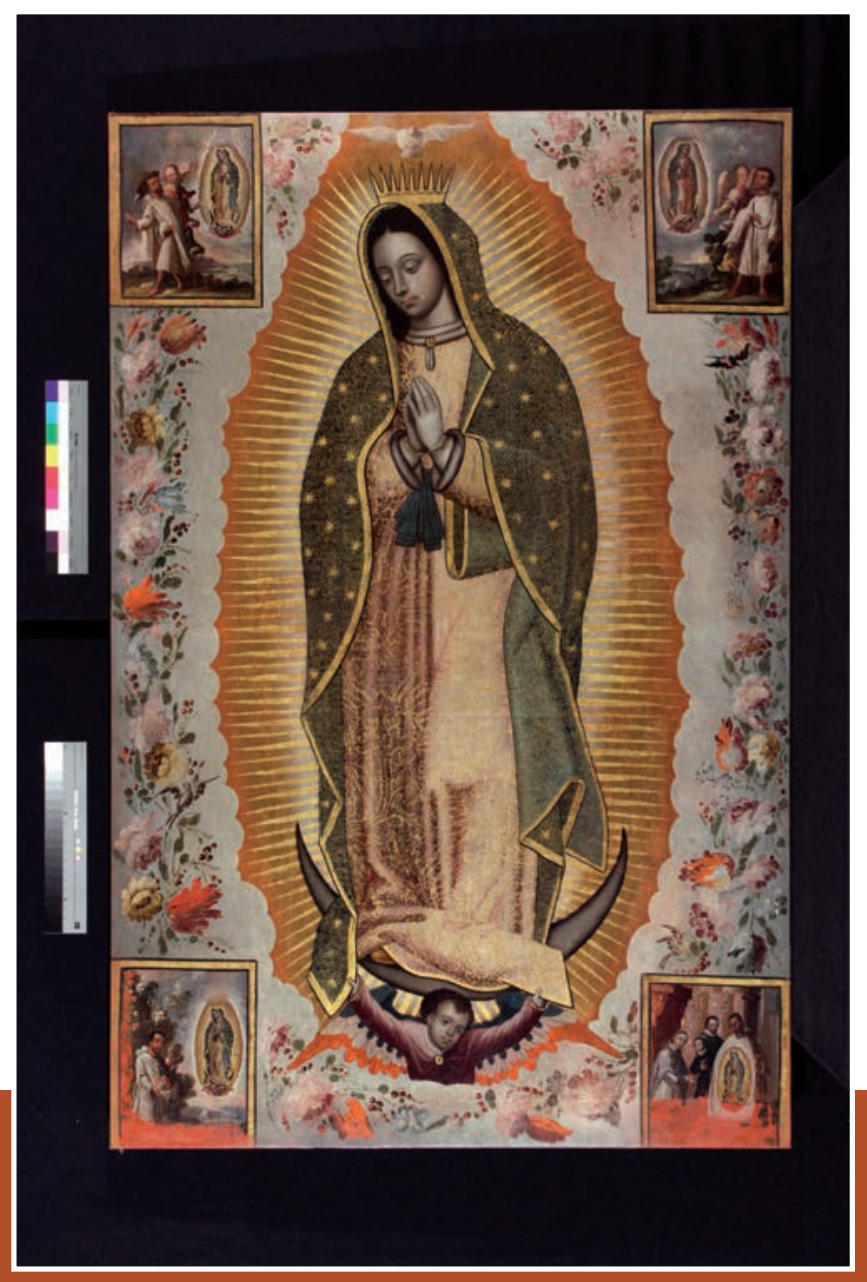

\section{Referencias}

Becerra Tango, Luis

1685 [1745] Felicidad de México en la admirable aparición de la Virgen María N. Señora de Guadalupe, y origen de su milagrosa imagen, que se venera en su santuario extramuros de aquella ciudad, Madrid, Imprenta de Juan de Zúñiga.

Benjamin, Walter

1989 "La obra de arte en la época de su reproductibilidad técnica", en Discursos interrumpidos I, Madrid, Taurus.

Brandi, Cesare

1963 Teoria del restauro, Roma, Edizioni di Storia e Letteratura.

Cabrera, Miguel

1756 Maravilla americana y conjunto de raras maravillas observadas con la dirección de las reglas del arte de la pintura, México, Antiguo Colegio de San Ildefonso.

Cuadriello, Jaime et al.

2004 "Zodíaco mariano: Una alegoría de Miguel Cabrera", en Zodíaco mariano. 250 años de la declaración pontificia de María de Guadalupe como patrona de México, México, Museo de la Basílica de Guadalupe / Museo Soumaya.

Panofsky, Erwin

1991 El significado de las artes visuales, Madrid, Alianza (Alianza Forma 4).

Pereda, Felipe

2007 Las imágenes de la discordia, Madrid, Marcial Pons.

Título en inglés: "Another painting? The uniqueness of the Virgin of Guadalupe from Ayapango" 